\title{
Demineralized bone matrix and calcium-phosphate cement in bone regeneration in rats ${ }^{1}$
}

Luiz Carlos Ferreira da Silva', Gabriela Granja Porto", Emanuel Sávio de Souza Andrade"I', José Rodrigues Laureano Filho'v

'PhD, Department of Oral and Maxillofacial Surgery, Universidade de Pernambuco (UPE), Recife-PE, Brazil. Acquisition, analysis and interpretation of data; manuscript preparation.

"PhD, Department of Oral and Maxillofacial Surgery, and Department of Forensic Science, UPE, Recife-PE, Brazil. Technical procedures, analysis and interpretation of data, manuscript preparation.

I'PhD, Department of Oral Pathology, UPE, Recife-PE, Brazil. Technical procedures, acquisition of data.

IVPhD, Department of Oral and Maxillofacial Surgery, UPE, Recife-PE, Brazil. Conception and design of the study, manuscript preparation, final approval.

\section{Abstract}

Purpose: To compare bone regeneration in critical-sized defects in rat calvarium using demineralized bone matrix and calcium phosphate cement.

Methods: Thirty Wistar rats were divided into 3 groups of 10 animals each. Two defects of $5-\mathrm{mm}$ were made in the parietal bones of each animal. Group I had calcium phosphate cement placed in the experimental defect, Group II had filled with demineralized bone matrix and Group III had with the combination of the matrix and cement in equal parts. All animals had one defect left unfilled to serve as controls. Five animals in each group were sacrificed at 4 and 8 weeks. Histomorphometric analysis was used to quantify the amount of new bone within the defects.

Results: The results showed that demineralized bone matrix-treated defects had significantly more new bone at 4 weeks compared to calcium phosphate cement-treated defects ( $p=0.03$ ) and also had significantly more new bone at 8 weeks compared to unfilled defects $(p=0.04)$. Conclusions: The demineralized bone matrix was superior to calcium phosphate cement in bone regeneration. It seems that calcium phosphate cement acted by inhibiting the osteogenesis when associated with a demineralized bone matrix and this combination should not be recommended.

Key words: Bone Matrix. Bone Regeneration. Rats. 


\section{Introduction}

The restoration of bone defects in the maxillofacial skeleton remains one of the most challenging problems faced by oral and maxillofacial surgeons ${ }^{1}$. Trauma, osteotomy sites, oncologic resections, infections, or developmental anomalies are clinical situations in which defects need to be reconstructed. In adults, only minor bone defects are capable of healing spontaneously ${ }^{2,3}$. The reason for this impaired defect healing seems to be related to the fast ingrowth of soft tissue, thus blocking bone formation at the edges of the defect and thereby preventing bone healing ${ }^{4}$.

Currently, autogenous bone grafts are the preferred material for craniofacial reconstruction ${ }^{5,6}$. Despite being highly effective, there are several problems associated with their use. Clinically, autogenous bone grafts may increase operative time and morbidity, they are often mechanically unstable during surgery, may be insufficient for reconstruction of large defects, and undergo significant resorption, thus requiring further bone grafting procedures ${ }^{7}$. Recently, to minimize these problems, interest has been shown in the use of allogenic and alloplastic bone substitutes. The ideal graft should be osteoinductive to stimulate osteogenesis and osteoconductive to provide a scaffold for establishing optimal conditions for ingrowth of blood vessels and cells with osteogenic potential ${ }^{5,6,8}$.

The demineralized allograft may be used as a matrix, especially since it is immunologically harmless, stimulates osteogenesis and is incorporated into the new bone formed ${ }^{6}$. Calcium phosphate cement has been used as a bone substitute for reconstruction of bone loss $^{8}$. It bonds chemically to the bone, restoring the contour and increasing the biomechanical property; in addition it can promote osteoinduction when in direct contact with the bone ${ }^{9,10}$.

The aim of this study was to compare bone regeneration in critical-sized defects in the calvarium of rats using demineralized bone matrix and calcium phosphate cement in the expectation that the use of the matrix and cement together would increase the osteoinductive and osteoconductive capacity of the bone defect.

\section{- Methods}

This research was approved by the Ethics Committee, Universidade de Pernambuco.

Thirty male Wistar rats were used for the experiment. The rats were divided into 3 groups of 10 animals each, according to the type of filling. Two calvarial defects (experimental and control) of 5-mm were made in the parietal bones of each animal. Group I had calcium phosphate cement (Bone Source', Leibinger, Dallas, TX, USA) placed in one defect, Group II had one defect filled with demineralized bone matrix (Gen-ox-org', Baumer, Mogi-Mirim, Brazil), and Group III had one defect filled with a combination of the matrix and cement in equal parts. All the animals had the other defect left unfilled to serve as controls.

The time of evaluation for all groups was at 4 and 8 weeks after the surgical procedure. Thus, five animals in each group were sacrificed at these times.

Thirty animals were submitted to surgery under general anesthesia, which was induced by muscular injection of ketamine and xylaxine diluted $1: 1$ in a dose of $0.1 \mathrm{ml}$ per 100 $\mathrm{g}$ of weight. A sagittal incision of approximately $10 \mathrm{~mm}$ was made from the fronto-nasal region to the occipital protuberance. Blunt dissection was created and the calvarium was exposed. 
A critical defect of $5 \mathrm{~mm}$ on both sides of the median suture was performed using a trephine, always taking care to avoid injuring the dura mater. One osteotomy was made more anteriorly than the other in order to avoid dislocation of the material from one cavity to another. The procedure was concluded with suture in layers using nylon.

After sacrifice, the specimens were fixed with $10 \%$ formaldehyde and decalcified in a solution of $0.5 \%$ nitric acid for about 15 days. Semi-serial sections with a thickness of $5 \mu \mathrm{m}$ were cut in the coronal plane, using the greatest diameter through the defect, and stained with haematoxylin and eosin.

The slides were submitted to histological study in order to observe the bone regeneration in a descriptive manner using scores (Chart 1). The overall area of the defect was considered for this classification, using slides until the middle of the defect was reached. The type of tissue reaction found in the bone defect was also observed, such as acute or chronic inflammation and foreign body reaction. The presence or absence of the material inserted was observed as well, the purpose being to detect its presence or absence rather than quantify it, which was done by histomorphometric analysis.

Histomorphometric analysis was used to quantify the amount of new bone within the defects using the Motic Images Advanced 3.0 Program (Micro-Optic Industrial Group CO. Ltda, Guiyang, China).

Chart 1 - Histopathological scores.

\section{1st Category: type of tissue found in the bone defect}

1 - presence of fibrous connective tissue

2 - presence of immature bone tissue

3 - presence of mature bone tissue

\section{- Statistics}

\section{A descriptive statistical analysis} calculated mean, median and standard deviation of control and test groups. Intragroup evaluation was carried out using the Wilcoxon test. The comparative evaluation between groups in the test cavities was performed using the paired comparison of KruskalWallis. A Statistically significant difference was considered at the $5.0 \%$ level.

\section{- Results}

There was bone formation (scores 2 and
3) in the experimental group (calcium phosphate cement) in almost all animals for both times of evaluation. There was foreign body reaction in almost all animals in the experimental group at 4 weeks of evaluation $(n=4)$, and no tissue reaction was observed, except in one animal, in the experimental group at 8 weeks $(n=4)$. The presence of the material inserted was seen in almost all animals in the experimental group for both times of evaluation ( $n=5$ at 4 weeks; $\mathrm{n}=3$ at 8 weeks) (Figures 1 and 2 ). 


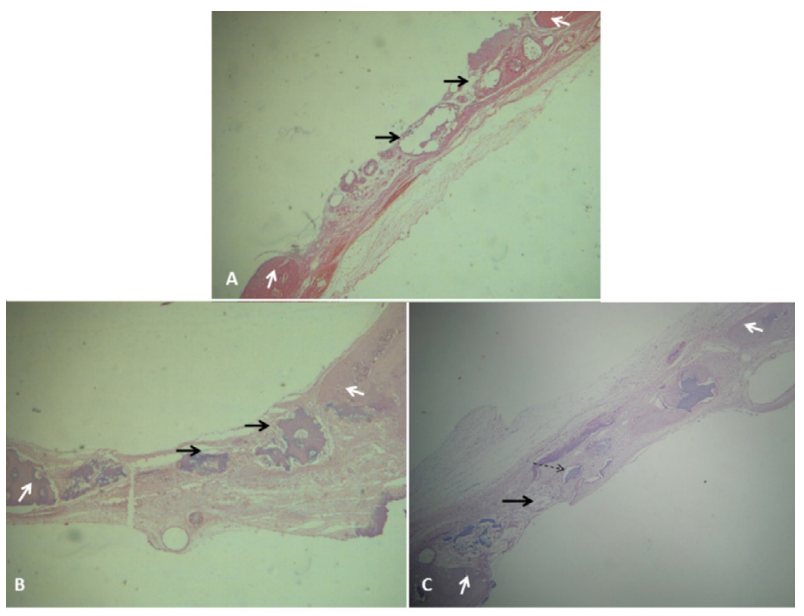

Figure 1 - Evaluation within 4 weeks $(A-C)$. A. Group I (calcium phosphate cement): bone defect extremities (white arrows) and empty spaces (black arrows) leaved by the material used during the decalcification process. B. Group II (demineralized bone matrix): particles of the material used (black arrows) in the center of the bone defect. C. Group III (matrix and cement): osteoid areas (black arrow) close to the inserted material (traced black arrow) (H\&E, x10).

There was bone formation (scores 2 and 3 ) in the experimental group (demineralized bone matrix) in almost all animals for both times of evaluation. There was foreign body reaction in half the animals in the experimental group at 4 weeks of evaluation $(n=3)$. The presence of the material inserted was seen in all animals in the experimental group at 4 weeks of evaluation $(n=5)$, and by 8 weeks the material had been absorbed in the experimental group. The presence of the material inserted was also observed in one animal in the control group at 4 weeks of evaluation (Figures 1 and 2).

There was bone formation (scores 2 and 3 ) in the experimental group (matrix and

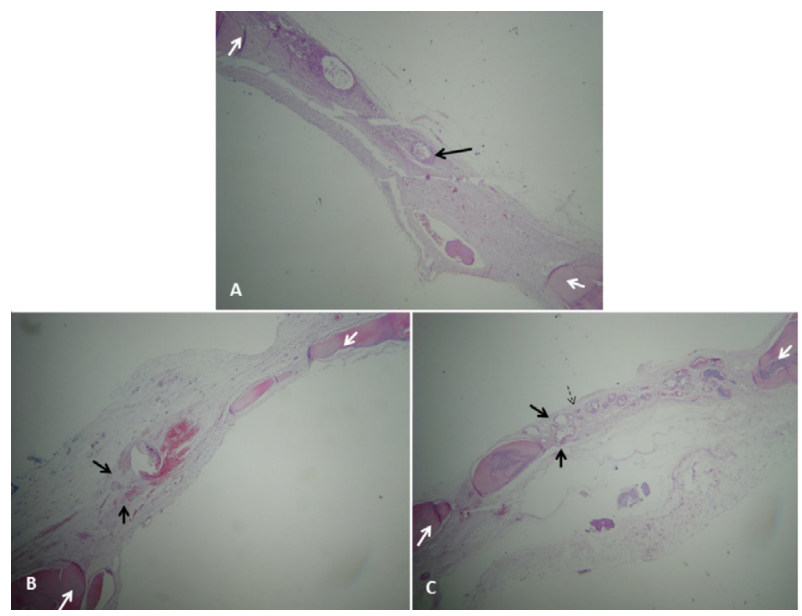

Figure 2 - Evaluation within 8 weeks (A-C). A. Group I (calcium phosphate cement): deposition of new bone around the place leaved by the particles of the material used during the decalcification process. B. Group II (demineralized bone matrix): material used (black arrows) being resorbed. C. Group III (matrix and cement): empty spaces (black arrows) leaved by the material used during the decalcification process and material used (traced black arrow) being resorbed $(\mathrm{H} \& \mathrm{E}, \mathrm{x} 10)$ (White arrows indicate the bone defect extremities in all figures).

cement) in almost all animals for both times of evaluation. There was foreign body reaction in about half the animals in the experimental group for both times of evaluation ( $n=3$ at 4 weeks; $n=2$ at 8 weeks). The material inserted was seen in all animals in the experimental group for both times of evaluation ( $n=5$ at 4 and 8 weeks). The presence of the material inserted was also observed in two animals in the control group at 8 weeks of evaluation (Figures 1 and 2).

Table 1 shows the mean, median and standard deviation of the hismorphometric bone gain according to group and time of evaluation for experimental and control defects (Figures 1 and 2). 
Table 1 - Mean, median and standard deviation of the quantity of bone tissue formed according to the group and time of evaluation.

\begin{tabular}{|c|c|c|c|}
\hline \multirow[b]{2}{*}{ Group } & \multirow[b]{2}{*}{ Statistics } & \multicolumn{2}{|c|}{ Time of evaluation } \\
\hline & & 4 weeks & 8 weeks \\
\hline & $\left(\mathrm{mm}^{2}\right)$ & & \\
\hline \multicolumn{4}{|c|}{ - Group I (calcium-phosphate cement) } \\
\hline \multirow[t]{3}{*}{ Control } & Mean & 0.0000 & 0.0000 \\
\hline & Median & 0.0000 & 0.0000 \\
\hline & Standard deviation & - & - \\
\hline \multirow[t]{3}{*}{ Test } & Mean & $0.0000^{(A)}$ & 0.0134 \\
\hline & Median & 0.0000 & 0.0000 \\
\hline & Standard deviation & - & 0.0280 \\
\hline Value of $p$ & & $\mathrm{P}^{(1)}=1.000$ & $\mathrm{p}^{(1)}=0.180$ \\
\hline \multicolumn{4}{|c|}{ - Group II (demineralized bone matrix) } \\
\hline \multirow[t]{3}{*}{ Control } & Mean & 0.0000 & 0.0000 \\
\hline & Median & 0.0000 & 0.0000 \\
\hline & Standard deviation & - & - \\
\hline \multirow[t]{3}{*}{ Test } & Mean & $0.1335^{(B)}$ & 0.0825 \\
\hline & Median & 0.1437 & 0.0642 \\
\hline & Standard deviation & 0.0885 & 0.0725 \\
\hline Value of $p$ & & $P^{(1)}=0.068$ & $\mathrm{p}^{(1)}=0.043^{*}$ \\
\hline \multicolumn{4}{|c|}{ - Group III (matrix and cement) } \\
\hline \multirow[t]{3}{*}{ Control } & Mean & 0.0147 & 0.0000 \\
\hline & Median & 0.0000 & 0.0000 \\
\hline & Standard deviation & 0.0202 & - \\
\hline \multirow[t]{3}{*}{ Test } & Mean & $\begin{array}{l}0.0745 \\
\text { (AB) }\end{array}$ & 0.0707 \\
\hline & Median & 0.0598 & 0.0290 \\
\hline & Standard deviation & 0.0734 & 0.1079 \\
\hline Value of $p$ & & $P^{(1)}=0.068$ & $\mathrm{p}^{(1)}=0.109$ \\
\hline Value of $p$ & & $\mathrm{p}^{(2)}=0.030^{*}$ & $\mathrm{p}^{(2)}=0.112$ \\
\hline
\end{tabular}

$\left({ }^{*}\right)$ - Statistically significant difference at the $5.0 \%$ level.

(1) - By means of Wilcoxon's signed posts test.

(2) - By means of the Kruskal-Wallis test for comparison between groups in the test cavities.

Note: If all the letters in parentheses are different, there is a significant difference between the means of the corresponding groups. 
Intragroup evaluation was carried out using the Wilcoxon test, which showed that only in Group II (demineralized bone matrix) was there a significant difference at 8 weeks of evaluation $(p=0.04)$. This indicates that there was more new bone formation in the experimental defects when compared to the control ones (Table 1).

The comparative evaluation of the groups was performed using the paired comparison of Kruskal-Wallis, which showed that only at 4 weeks of evaluation was there a significant difference $(p=0.03)$. This indicates that there was more new bone formation in Group II (demineralized bone matrix) when compared to the other groups, as shown in Table 1.

\section{- Discussion}

The regeneration capacity of bone presents limitations and in many cases the reconstruction of the defects is necessary, as in traumas, oncologic resections, infections, or prior to the placement of dental implants, 11,12. The reconstructions may be done with autogenous bone and synthetic or natural material ${ }^{13-16}$.

Autogenous bone is regarded as the material of choice for bone reconstructions, although it may present some disadvantages such as greater surgical morbidity due to the need for a second surgical site ${ }^{17}$. In addition, many factors may change the initial result with bone grafts, particularly as a result of postoperative bone resorption ${ }^{18}$.

Several materials have been studied and used as bone substitutes in order to avoid the use of autogenous bone ${ }^{19}$. Among these, demineralized bone matrix ${ }^{7,13,18}$ and calcium phosphate cement ${ }^{2,14,20,21}$ deserve special mention. The present study used bovine demineralized bone matrix (Gen-oxorg $^{\circ}$, Baumer) based on Torricelli et al..$^{25}$, who showed that xenogenous materials may be more osteoinductive than human ones.

A demineralized bone matrix has been shown to be inert from the immunologic point of view, stimulates osteogenesis, is incorporated into the body and replaced with new bone from the hostage ${ }^{6,7}$. In this study, the matrix proved to be biocompatible, because even though there was an inflammatory reaction and the presence of giant cells at 4 weeks of evaluation, at 8 weeks this reaction was mild and there were no giant cells at all.

In relation to the calcium phosphate cement, in this study, at 4 and 8 weeks the presence of giant cells was observed near the particles of the material. It is important to note that during the process of histological decalcification the material is lost, leaving a gap corresponding to the material. This is in agreement with the studies of Indovina Jr. and Block ${ }^{22}$, and Moghadam et al. ${ }^{12}$, who observed an inflammatory reaction and giant cells around the spaces corresponding to the particles of the material at 8 and 12 weeks of evaluation.

In this study, when the matrix was associated with the cement, for both times of evaluation, there were giant cells. When the matrix was used alone, these cells were only observed at 4 weeks of evaluation. This suggests that the presence of calcium phosphate cement could be the determining factor for the maintenance of the inflammatory reaction and the presence of giant cells.

According to Moghadan et al. ${ }^{12}$, the bleeding during or after the surgical procedure may account for the inappropriate hardening of the cement and for the presence of an inflammatory reaction.

The presence of giant cells noted in this study may be related to the resorption of the particles of the material. These cells may originate from the clastic cells, which are responsible for resorption and remodeling the area. These cells were seen in all experimental defects at 4 weeks of evaluation. In the matrix group, these cells were no longer seen at 8 weeks. This could be due to the greater velocity of resorption of the particles of the matrix when compared to the cement, which is in agreement with Clokie et al..$^{20}$, and Moghadan et al. ${ }^{12}$. 
The new bone formation in the experimental groups of this study was greater in the experimental defects than in the control ones (filled with blood clots) with a significant statistical difference at 8 weeks of evaluation in group II (bone matrix) $(p=0.043)$. This is in agreement with Laureano Filho ${ }^{19}$ and Torriceli et $a l .{ }^{22}$, who found greater bone formation in the defects that were filled with demineralized bone matrix than in the one filled only with blood clots.

The ossification observed in this study was intramembranous, although in some studies it was endochondral or intramembranous ${ }^{18,23}$.

When the cement was placed with a demineralized bone matrix, the mean of new bone formation was less than when the matrix was used alone, and greater when compared to the use of cement alone, although there was no significant difference. These findings may suggest that the cement was an osteogenesis inhibitor, because it acts as a hydroxyapatite bloc even though it has micropores. The development of calcium phosphate cements with larger pores may increase bone formation. Moreover, the addition of osteoinductive factors, such as morphogenetic proteins, may increase the resorption rate and at the same time stimulate bone formation ${ }^{11,12}$.

\section{Conclusions}

The demineralized bone matrix was superior to calcium phosphate cement in bone regeneration. It seems that calcium phosphate cement acted by inhibiting the osteogenesis when associated with a demineralized bone matrix and this combination should not be recommended

\section{References}

1. Bosch C, Melsen B, Vargervik K. Importance of the critical-size bone defect in testing bone-regenerating materials. J Craniofac Surg. 1998 Jul;9(4):310-6. PMID: 9780924.

2. Isaksson $S$, Alberius P. Comparison of regenerative capacity elicited by demineralized bone matrix of different embryonic origins. J Craniomaxillofac Surg. 1992 Feb-Mar;20(2):73-80. PMID: 1569218.

3. Iatecola A, Barraviera B, Junior RS, Santos GR, Neves JI, Cunha MR. Use of a new fibrin sealant and laser irradiation in the repair of skull defects in rats. Braz Dent J. 2013 Sep-Oct;24(5):456-61. doi: 10.1590/01036440201302265.

4. Schortinghuis J, Ruben JL, Raghoebar $\mathrm{GM}$, Stegenga B. Ultrasound to stimulate mandibular bone defect healing: a placebocontrolled single-blind study in rats. J Oral Maxillofac Surg. 2004 Feb;62(2):194-201. PMID: 14762752.

5. Pallesen L, Schou S, Aaboe M, HjørtingHansen E, Nattestad A, Melsen F. Influence of particle size of autogenous bone grafts on the early stages of bone regeneration: a stereologic study in rabbit calvarium. Int J Oral Maxillofac Implants. 2002 JulAug;17(4):498-506. PMID: 12182292.

6. Sawada K, Nakahara K, Haga-Tsujimura $M$, lizuka T, Fujioka-Kobayashi $M$, Igarashi K, Saulacic N. Comparison of three block bone substitutes for bone regeneration: long-term observation in the beagle dog. Odontology. 2018 Mar 20. doi: 10.1007/ s10266-018-0352-7. [Epub ahead of print]

7. Jazayeri MA, Nichter LS, Zhou ZY, Wellisz T, Cheung DT. Comparison of various delivery systems for demineralized bone matrix in a rat cranial defect model. J Craniofac Surg. 1994 Jul;5(3):172-8; discussion 179. PMID: 7803589.

8. Diker N, Gulsever S, Koroglu T, Yilmaz Akcay E, Oguz Y. Effects of hyaluronic acid and hydroxyapatite/beta-tricalcium phosphate in combination on bone regeneration of a critical-size defect in an experimental model. J Craniofac Surg. 2018 Feb 12. doi: 10.1097/SCS.0000000000004338. [Epub ahead of print]

9. Schmitz JP, Hollinger JO, Milam SB. Reconstruction of bone using calcium phosphate bone cements: a critical review. J Oral Maxillofac Surg. 1999 Sep;57(9):11226. PMID: 10484115.

10.Kamal M, Andersson L, Tolba R, Al-Asfour A, Bartella AK, Gremse F, Rosenhain S, Hölzle F, Kessler $\mathrm{P}$, Lethaus $\mathrm{B}$. Bone regeneration using composite non-demineralized xenogenic dentin with beta-tricalcium phosphate in experimental alveolar cleft repair in a rabbit 
model. J Transl Med. 2017 Dec 23;15(1):263. PMID: 29274638.

11.Clokie CM, Moghadam H, Jackson MT, Sandor GK. Closure of critical sized defects with allogenic and alloplastic bone substitutes. J Craniofac Surg. 2002 Jan;13(1):111-21; discussion 122-3. PMID: 11887007.

12. Moghadam HG, Sándor GK, Holmes HH, Clokie CM. Histomorphometric evaluation of bone regeneration using allogeneic and alloplastic bone substitutes. J Oral Maxillofac Surg. 2004 Feb;62(2):202-13. PMID: 14762753.

13.Bender SA, Rogalski JB, Mills MP, Arnold RM, Cochran DL, Mellonig JT. Evaluation of demineralized bone matrix paste and putty in periodontal intraosseous defects. $J$ Periodontol. 2005 May;76(5):768-77. PMID: 15898938.

14.Gómez E, Martín M, Arias J, Carceller F. Clinical applications of Norian SRS (calcium phosphate cement) in craniofacial reconstruction in children: our experience at Hospital La Paz since 2001. J Oral Maxillofac Surg. 2005 Jan;63(1):8-14. PMID: 15635550.

15. Rabie AB, Chay SH, Wong AM. Healing of autogenous intramembranous bone in the presence and absence of homologous demineralized intramembranous bone. Am J Orthod Dentofacial Orthop. 2000 Mar;117(3):288-97. PMID: 10715088.

16.Stanton DC, Chou JC, Carrasco LR. Injectable calcium-phosphate bone cement (Norian) for reconstruction of a large mandibular defect: a case report. J Oral Maxillofac Surg. 2004 Feb;62(2):235-40. PMID: 14762758.

17.Orsini G, Ricci J, Scarano A, Pecora G, Petrone G, lezzi G, Piattelli A. Bone-defect

\section{Correspondence:}

Dr. José Rodrigues Laureano Filho

Faculdade de Odontologia de Pernambuco

Departamento de Cirurgia e Traumatologia Buco-Maxilo-Facial

Avenida General Newton Cavalcanti, 1650

54753-220 Camaragibe - PE Brasil

Tel.: (55 81)3458-2867

laureanofilho@gmail.com

Received: Dec 09, 2017

Review: Feb 08, 2018

Accepted: Mar 12, 2018 healing with calcium-sulfate particles and cement: an experimental study in rabbit. J Biomed Mater Res B Appl Biomater. 2004 Feb 15;68(2):199-208. PMID: 14737769.

18. Rabie $A B$, Lie Ken Jie RK. Integration of endochondral bone grafts in the presence of demineralized bone matrix. Int J Oral Maxillofac Surg. 1996 Aug;25(4):311-8. PMID: 8910120.

19.Laureano Filho JR, Castelo Branco BL, Andrade ES, Barbosa JR. Histological comparison of demineralized bone matrix and the Ricinus communis polymer on bone regeneration. Rev Bras Otorrinolaringol (Engl Ed). 2007 Mar-Apr;73(2):186-92. PMID: 17589726.

20.Frankenburg EP, Goldstein SA, Bauer TW, Harris SA, Poser RD. Biomechanical and histological evaluation of a calcium phosphate cement. J Bone Joint Surg Am. 1998 Aug;80(8):1112-24. PMID: 9730120.

21. Kirschner RE, Karmacharya J, Ong G, Gordon AD, Hunenko O, Losee JE, Gannon FH, Bartlett SP. Repair of the immature craniofacial skeleton with a calcium phosphate cement: quantitative assessment of craniofacial growth. Ann Plast Surg. 2002 Jul;49(1):33-8; discussion 38. PMID: 12142592.

22. Indovina A Jr, Block MS. Comparison of 3 bone substitutes in canine extraction sites. J Oral Maxillofac Surg. 2002 Jan;60(1):53-8. PMID: 11757008.

23.Stavropoulos A, Kostopoulos L, Mardas $\mathrm{N}$, Karring T. Influence of demineralized bone matrix's embryonic origin on bone formation: an experimental study in rats. Clin Implant Dent Relat Res. 2003;5(3):18492. PMID: 14575635.

Conflict of interest: none

Financial source: none
${ }^{1}$ Research performed at Department of Oral and Maxillofacial Surgery, Universidade de Pernambuco (UPE), Recife-PE, Brazil. 